\title{
MUHAMMADIYAH YOUTH MOVEMENT ENTREPRENEUR SCHOOL, KURSUS KEWIRAUSAHAAN SINGKAT UNTUK REMAJA AKTIVIS ORTOM MUHAMMADIYAH MALANG
}

\author{
Ahmad Shobrun Jamil ${ }^{1)}$ \\ ${ }^{1)}$ Sentra Hak Kekayaan Intelektual Universitas Muhammadiyah Malang, Malang, Jawa Timur, Indonesia \\ Corresponding author : Ahmad Shobrun Jamil1 \\ E-mail : : shobrun@umm.ac.id
}

Diterima 17 September 2020, Direvisi 22 September 2020, Disetujui 23September 2020

\begin{abstract}
ABSTRAK
Muhammadiyah Youth Movement Enterpreneur Malang bertujuan untuk melatih para calon wirausahawan muda aktivis Organisasi Otonom (ORTOM) Muhammadiyah di kota Malang. Untuk membuat sistem yang baku maka akan dilaksanakan fokus grup diskusi dengan beberapa pakar ahli dalam bidang pendidikan maupun dalam bidang praktisi entrepreneurship di Malang yang kemudian disusun dalam sebuah naskah standar operasional prosedur dan dijadikan acuan dalam pelaksanaan AMM entrepreneur school selanjutnya. Selain itu akan dibuat berbagai komponen pembelajaran mulai rancangan pembelajaran pelaksanaan pembelajaran perangkat pelaksanaan pembelajaran sistem evaluasi. Pelatihan memberikan dampak yang positif bagi peserta. Mereka semakin tahu dengan skema kanvas bisnis dan model bisnis modern. Dan hal-hal diatas memberikan beberapa pelajaran dan rekomendasi untuk pelatihan batch mendatang diperlukan pengelompokan usaha yang sama dalam starting point usaha dan tingkat pengetahuan peserta sehingga materi dapat diberikan dengan maksimal.
\end{abstract}

Kata Kunci: pengabdian; entrepreneur; AMM; pembelajaran; pelatihan; usaha.

\begin{abstract}
Muhammadiyah Youth Entrepreneur Movement Malang aims to train aspiring young entrepreneurial activists of the Muhammadiyah Autonomous Organization (ORTOM) in Malang city who have small businesses or micro businesses in their respective places to be able to improve the quality and quantity of their business. To create a standard system, focus group discussions will be carried out with several expert experts in the field of education and in the field of entrepreneurship practitioners in Malang which are then compiled in a standard operating procedure script which is then used as a reference in the implementation of the next AMM entrepreneur school. In addition, various learning components will be made starting from the learning design of the learning implementation of the evaluation system learning implementation tools. The training has a positive impact on the participants. They are increasingly familiar with business canvas schemes and modern business models. And the things above provide some lessons and recommendations for the next batch of training, it is necessary to group the same efforts in starting the business points and the level of knowledge of the participants so that the material can be given optimally.
\end{abstract}

Keywords: dedication; entrepreneur; AMM; learning; training; business.

\section{PENDAHULUAN}

Progam pengabdian dalam proposal ini memilih Anggota pengurus pemuda Muhammadiyah Kota Malang sebagai mitra penyelenggara. Entrepreneur school ini adalah kursus kewirausahaan yang digagas bersama atara pengusul bersama Pimpinan Daerah Pemuda Muhammadiyah (PDPM) Kota Malang. Muhammadiyah. Youth Movement Enterpreneur Malang bertujuan untuk melatih para calon wirausahawan muda atau juga para di kota Malang yang memiliki usaha kecil atau usaha mikro di tempatnya masing-masing untuk meningkatkan usahanya. Program ini penting dilakukan untuk mendorong meningkatnya jumlah wirausahawan muda, sebab pendidikan kewirausahaan sangat berpengaruh positif terhadap minat dan niat berwirausaha (Adnyana \& Purnami, 2016). Selama ini Muhammadiyah sebagai organisasi dikenal bergerak dalam bidang pendidikan dan Kesehatan (Huda \& Kusumawati, 2019; Rusydi, 2016). Dalam konteks kegiatan ini, pengusul bermaksud untuk memperluas ranah Gerakan pendidikan dan ekonomi melalui $A M M$ Entrepreneur School.

Latar belakang diselenggarakannya Muhammadiyah Youth Movement Enterpreneur 
Malang ini karena melihat latar belakang dari anggota Pemuda Muhammadiyah yang aktif ikut berjuang dan berdakwah melalui organisasi angkatan muda Muhammadiyah sebagian besar masih belum bekerja yakni sebesar $28,7 \%$, sementara itu sebagian juga bekerja namun dengan gaji dibawah standar minimum upah kota sekitar 27,7\%, kemudian Penghasilan Rp500.000 sampai dengan 1 juta perbulan sekitar $19,5 \%$, dan hanya sedikit kurang dari $5 \%$ yang bergaji di atas 3 juta maupun Rp5.000.000, seperti yang ditunjukkan pada Gambar 1.

\section{Pendapatan Bulanan}
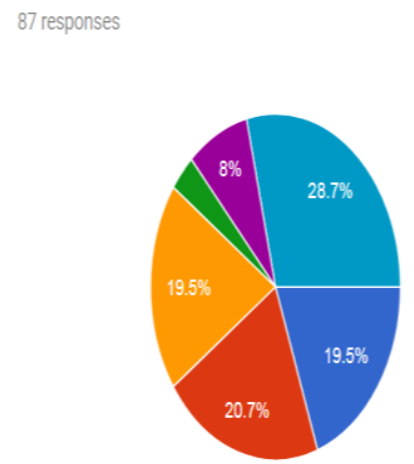

500 ribu s.d 1 Juta Rupiah 1 Juta s.d 2 Juta Rupiah 2 Juta s.d 3 Juta Rupiah - 3 Juta s.d 5 Juta Rupiah Diatas 5 Juta Rupiah - Belum Bekerja

Gambar 1. Pendapatan Bulanan Anggota dan Pengurus Angkatan Muda Muhammadiyah Kota Malang (Data tahun 2018)

Sementara itu mereka rata-rata adalah kepala keluarga yang memiliki tanggungan keluarga tercatat dalam survei yang dilakukan $24,1 \%$ anggota adalah menanggung 3 orang anggota keluarganya $21,8 \%$ mengandung 2 orang anggota keluarganya 13,8\% menanggung lebih dari 3 orang keluarga, seperti yang ditunjukkan pada Gambar 2.

Keluarga yang menjadi tanggungan saat ini 87 responses
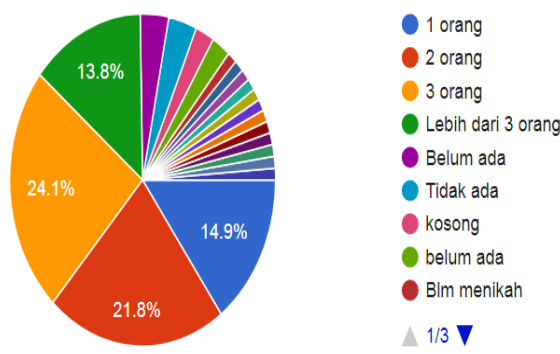

Gambar 2. Tanggungan keluarga anggota Pemuda Muhammadiyah Kota Malang (data tahun 2018)

Adapun terkait dengan sebaran tempat atau lokasi atau tempat tinggal mereka ditunjukkan oleh Gambar 3, dimana para anggota aktivis Pemuda Muhammadiyah maupun angkatan muda Muhammadiyah Ini pertama $23 \%$ mereka adalah warga dari Kecamatan Sukun 19,5\% adalah warga Kecamatan Blimbing $27 \%$ adalah warga Kecamatan Kedungkandang, 14,9\% Kecamatan Lowokwaru.

\section{Utusan PCM}

87 responses

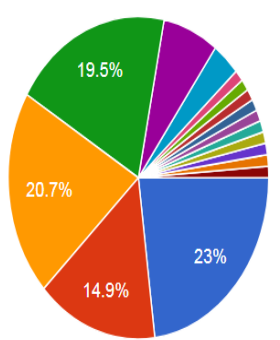

$$
\begin{aligned}
& \text { PCM Sukun } \\
& \text { PCM Lowokwaru } \\
& \text { PCM Kedungkandang } \\
& \text { PCM Blimbing } \\
& \text { PCM Klojen } \\
& \text { Klojen } \\
& \text { Pdpm } \\
& \text { KLOJEN } \\
& \text { PDPM KOTA MALANG } \\
& 1 / 2
\end{aligned}
$$

Gambar 3. Sebaran wilayah anggota AMM Kota Malang (data tahun 2018)

Rata-rata mereka adalah pekerja yang belum tetap serabutan pengusaha mikro antara lain yang terdata mereka adalah pedagang buah pedagang makanan ringan anak-anak pedagang cilok kemudian pedagang bakso kemudian ada yang jadi konveksi penyedia layanan antar jemput penyedia katering pengrajin dan lain-lain. Berdasarkan data yang ada di atas memang hal ini menunjukkan para anggota tersebut, mereka memerlukan bantuan agar usaha mereka berkembang lebih baik segalanya bisa ditingkatkan omsetnya bisa dinaikkan sehingga kebutuhan dasar mereka untuk memenuhi kebutuhan keluarga terpenuhi dan dapat membantu secara umum gerak dakwah persyarikatan karena urusan dari rumah tangga mereka masing-masing terselesaikan. Hal ini penting bagi kelangsungan organisasi dakwah yang bermisi untuk memberi pengaruh pada masyarakat sebab posisi sosial seseorang di masyarakat menentukan keberhasilan perubahan sebagai visi organisasi (Suddaby et al., 2016)

Maka kemudian pengusul bersama pimpinan daerah Pemuda muhammadiyah kota Malang periode 2018-2022 bersepakat untuk melanjutkan program yang dahulunya bernama AMM Enterprener School dan kini di persempit khusus untuk pengurus pemuda muhammadiyah kota Malang. Penyempitan sasaran peserta ini bertujuan agar program kegiatan lebih mendapatkan atensi dan keseriusan peserta. Berdasarkan penelitian (Santy et al., 2017) diketahui bahwa pengetahuan awal berwirausaha dan motivasi 
diri karena latar belakang ekonomi menjadi pemicu minat belajar berwirausaha.

Karena dikelola bersama dengan PDPM Kota Malang sebagai organisasi non profit yang terus melakukan pergantian pengurus secara periodik, maka akan muncul problem manakala program yang sudah disusun dan telah dilaksanakan dengan baik tidak dilanjutkan oleh pengurus berikutnya karena minimnya dokumen kegiatan dan sistem kegiatan yang mapan. Oleh karena itu perlu manajemen yang bagus dan adanya pendokumentasian data yang mumpuni dalam kegiatan ini. Selama dalam pelaksanaannya selama satu tahun berjalan ini, memang belum ada struktur kurikulum yang tetap, termasuk pemateri, honorarium, buku modul, buku penugasan, presensi dan segala macam atribut evaluatif yang harusnya ada dalam sebuah Lembaga Kursus pelatihan ataupun lembaga pendidikan.

Oleh karena itu dirasa perlu oleh angkatan muda Muhammadiyah disusunnya sebuah kurikulum yang baku sistematika yang pas dan menjamin keberlanjutannya karena dirasa program ini adalah program baik yang terus perlu dilanjutkan oleh penguruspengurus.

\section{METODE}

Dalam metode pelaksanaan kegiatan ini akan disampaikan beberapa solusi dari hasil pemetaan permasalahan maupun analisis situasi pada bagian pendahuluan. Sebagai suatu program yang bermanfaat bagi anggota angkatan muda Muhammadiyah khususnya dan warga muda kota Malang pada umumnya AMM entrepreneur school dirasa belum memiliki satu sistem pembelajaran yang baku dan integratif. Salah satu parameter yang menunjukkan hal itu adalah belum adanya modul yang disusun oleh $A M M$ entrepreneur school. Disamping juga berbagai macam perangkat pembelajaran dan evaluasi yang memang belum tersusun. Oleh karenanya dalam metode pelaksanaan ini yang akan dilakukan adalah mengatasi permasalahan keadaan dari sistem yang baku dari $A M M$ entrepreneur school ini.

Untuk membuat sistem yang baku maka akan dilaksanakan fokus grup diskusi dengan beberapa pakar ahli dalam bidang pendidikan maupun dalam bidang praktisi enterpreneurship yang kemudian disusun dalam sebuah naskah standar operasional prosedur yang kemudian dijadikan acuan dalam pelaksanaan $A M M$ entrepreneur school selanjutnya. Selain itu di akan dibuat berbagai komponen pembelajaran mulai rancangan pembelajaran pelaksanaan pembelajaran perangkat pelaksanaan pembelajaran sistem evaluasi.

Tabal 1. Tahapan Pelaksanaan Kegiatan

\begin{tabular}{|c|c|c|c|}
\hline $\begin{array}{l}\mathbf{N} \\
\mathbf{0}\end{array}$ & Kegiatan & $\begin{array}{c}\text { Komponen } \\
\text { yang } \\
\text { Terlibat }\end{array}$ & $\begin{array}{c}\text { Indikator } \\
\text { Keberhasil } \\
\text { an }\end{array}$ \\
\hline 1. & $\begin{array}{l}\text { Sosialisasi } \\
\text { dan fokus } \\
\text { grup diskusi } \\
\text { program IbM } \\
\text { Muhammadiy } \\
\text { ah Youth } \\
\text { Movement } \\
\text { Enterpreneur } \\
\text { Malang }\end{array}$ & $\begin{array}{l}\text { Pengusul, } \\
\text { Ketua PDPM } \\
\text { Kota } \\
\text { Malang, } \\
\text { Wakil Ketua } \\
\text { bidang } \\
\text { Kewirausaha } \\
\text { an dan } \\
\text { Anggota }\end{array}$ & $\begin{array}{l}\text { Tersepakati } \\
\text { jadwal } \\
\text { pembinaan } \\
\text { dan skema } \\
\text { pembinaan } \\
\text { enterprenur } \\
\text { PDPM Kota } \\
\text { Malang }\end{array}$ \\
\hline 2. & $\begin{array}{l}\text { Perumusan } \\
\text { hasil FGD } \\
\text { oleh tim IbM } \\
\text { dan mitra } \\
\text { AMM }\end{array}$ & $\begin{array}{l}\text { AMM dan } \\
\text { tim IbM }\end{array}$ & $\begin{array}{l}\text { Tersusun } \\
\text { buku } \\
\text { panduan } \\
\text { pelaksanaa } \\
\mathrm{n} \text { AMM } \\
\text { enterprene } \\
\text { ur school }\end{array}$ \\
\hline 3. & $\begin{array}{l}\text { Seleksi } \\
\text { peserta }\end{array}$ & $\begin{array}{l}\text { Pengusul } \\
\text { dan Panitia } \\
\text { PDPM }\end{array}$ & $\begin{array}{l}\text { Diperoleh } \\
\text { peserta } \\
\text { yang } \\
\text { komitmen } \\
\text { dan sesuai } \\
\text { target } \\
\text { penjaringan }\end{array}$ \\
\hline 4. & $\begin{array}{l}\text { Pelaksanaan } \\
\text { pelatihan (12 } \\
\text { kali tatap } \\
\text { muka) }\end{array}$ & $\begin{array}{l}\text { Pengusul, } \\
\text { Panitia } \\
\text { PDPM dan } \\
\text { Coach } \\
\text { Enterpreneur }\end{array}$ & $\begin{array}{l}\text { Dihadiri } \\
80 \% \text { hingga } \\
\text { program } \\
\text { selesai }\end{array}$ \\
\hline 5. & $\begin{array}{l}\text { Monitoring } \\
\text { perkembang } \\
\text { an usaha }\end{array}$ & $\begin{array}{l}\text { Pengusul, } \\
\text { Panitia } \\
\text { PDPM dan } \\
\text { peserta } \\
\text { kegiatan }\end{array}$ & $\begin{array}{l}\text { Ada } \\
\text { progres } \\
\text { peningkata } \\
\text { n usaha } \\
\text { pasca } \\
\text { pelatihan }\end{array}$ \\
\hline 6. & $\begin{array}{l}\text { Penyusunan } \\
\text { Laporan }\end{array}$ & $\begin{array}{l}\text { Pengusul, } \\
\text { Panitia } \\
\text { PDPM dan } \\
\text { peserta } \\
\text { kegiatan }\end{array}$ & $\begin{array}{l}\text { Laporan } \\
\text { akhir dan } \\
\text { artikel } \\
\text { ilmiah }\end{array}$ \\
\hline
\end{tabular}

\section{HASIL DAN PEMBAHASAN}

Program pengabdian ini memiliki sasaran yaitu anggota pemuda Muhammadiyah kota malang. Langkah pertama yang dilaksanakan dalam program ini adalah penyusunan mini kurikulum oleh pengusul bersama tim ekonomi dan kewirausahaan IMM cabang malang dan Pemuda Muhammadiyah Kota Malang. Hasilnya adalah desain rencana up grading anggota Angkatan muda Muhammadiyah yang terdiri dari unsur anggota pemuda Muhammadiyah, Ikatan Mahasiswa Muhammadiyah, Ikatan Pelajar Muhammadiyah dan Nasyiatu Aisyiyah. Gambaran sederhana dari program ini adalah mini incubator bisnis yang mirip dengan yang 
dilaksanakan oleh Universitas Muhammadiyah Jakarta (Jaharuddin et al., 2019).

Program ini memiliki prasyarat diikuti oleh anggota yang telah memiliki usaha maupun yang memiliki niatan untuk menjadi entrepreneur. Terkumpul sejumlah peserta dengan latar belakang pemilik catering aqiqah, catering rumahan, pengrajin hiasan dekorasi rumah, penjual cilok, distributor buku, distributor kopi dan produk pertanian, pengusaha warung makan mahasiswa, dan beberapa mahasiswa semester akhir yang memiliki minat berwirausaha. Program dilaksanakan free charge namun konsekwensinya peserta wajib hadir di seluruh kegiatan, $2 x$ tidak hadir maka langsung gugur sebagai peserta dan tidak mendapat fasilitas hingga akhir pelatihan.

Adanya silabus dan rencana pembelajaran yang terarah dan terencana memberikan dampak positif pada pelaksanaan program ini. Berdasarkan (Anggraeni \& Akbar, 2018) perencanaan pembelajaran yang baik akan sangat menentukan keberhasilan belajar. Oleh karena itu perapian manajemen belajar dalam kegiatan ini dilakukan dengan sistematis. Disamping itu, pembelajaran dipadukan antara metode klasikal dan pembelajaran terjun langsung di lapang, yaitu belajar langsung di lokasi pengusaha membuka bisnisnya. Hal ini memiliki dampak positif dalam memotivasi dan menaikkan efikasi diri peserta dalam berwirausaha (Dewi \& Hadi, 2019)

Peserta mendapatkan pelatihan secara langsung dengan pola dua kali materi teori di kelas dan sekali ke lapang (belajar langsung pada pengusaha sukses di lokasi usahanya). Hal ini dilaksanakan beberapa putaran. Putaran pertama dua kali teori dilaksanakan di kantor PDM Kota malang dan di lapang di resto nasi goreng rendang ranjau di dekat pasar tawangmangu. Putaran kedua dilaksanakan dua kali teori di kampus II UMM dan di lapang dilaksanakan di resto ayam goreng Eat $O$ Clock, dilanjutkan putaran berikutnya di pemilik Kayana Kebab, Tatawarna Group dan IMarks Group. Kesediaan pemilik-pemilik usaha untuk ikut membina peserta kegiatan ini tak lepas dari pemahaman bahwa keberlanjutan usaha sangat ditentukan oleh keluasan jejaring dan kreativitas mereka dalam membuat pola relasi sosial dengan pelanggan (Dentchev et al., 2016)

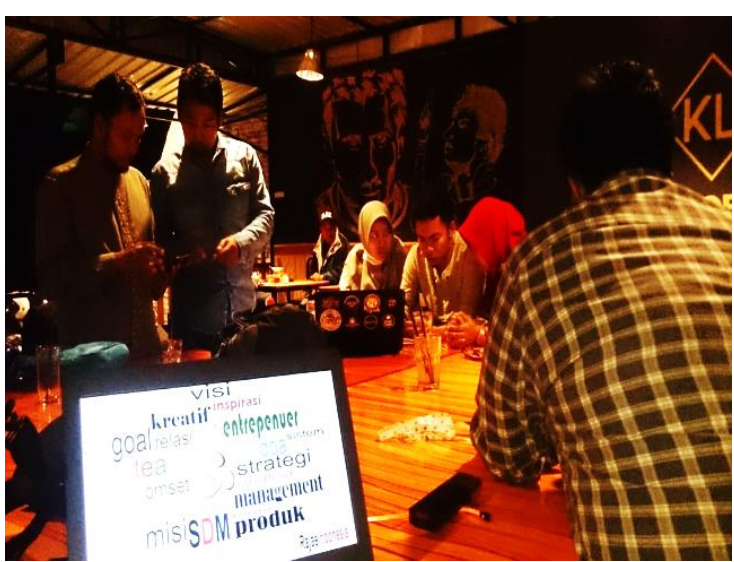

Gambar 4. Salah satu gambaran kegiatan belajar langsung di tempat usaha milik salah satu pemateri Muhammadiyah Youth

Movement Entrepreneur School.

Di dalam pelatihan, salah satu hal yang menjadi fokus adalah optimalisasi media sosial sebagai alat pemasaran. Hal ini penting sebab media sosial saat ini memegang peranan kunci dalam pemasaran (Martín-Rojas et al., 2020). Didalam pelatihan ini, Business model canvas menjadi salah satu pokok materi bisnis, sebab model ini dirasa pengusul memiliki kelengkapan gambaran terhadap peta bisnis dan berbagai hal yang sangat perlu disimulasikan dalam pelatihan bisnis (Türko, 2016).

Pelatihan ini dirasakan manfaatnya oleh peserta yang telah tergabung dan berkomitmen menyelesaikan pelatihan hingga rangkaian terakhir. Walaupun tidak semua usaha yang dijalankan peserta langsung mendapatkan kenaikan omset, namun wawasan dan gambaran bisnis telah membuka kebuntuan pemikiran peserta untuk berkembang dan berdaya saing.

Misalnya katering aqiqah persada (Gambar 4), setelah mengikuti pelatihan ini kemudian melakukan modernisasi dalam pencatatan aset dan omset serta modernisasi sistem pemasaran yang up to date menggunakan media sosial Instagram, facebook marketplace dan pendekatan pemasaran visual fotografis yang semakin menarik. Distributor buku Amanah, pasca pelatihan semakin meningkatkan MSN (meet some one new) dan DSN (do something new) nya dan berhasil meningkatkan omset penjualan. Namun ada juga yang gagal dalam memperbaiki performa seperti penjual cilok, yang kemudian menutup usaha ciloknya dan berganti ke usaha leker. Hasil penelusuran, hal ini disebabkan karena peserta tersebut kurang open mind dan kendala lain karena tingkat pendidikannya yang rendah. 


\section{SIMPULAN DAN SARAN}

Pelatihan memberikan dampak yang positif bagi peserta. Mereka semakin tahu dengan skema kanvas bisnis dan model bisnis modern. Dan hal-hal diatas memberikan beberapa pelajaran dan rekomendasi untuk pelatihan batch mendatang diperlukan pengelompokan usaha yang sama dalam starting poin usaha dan tingkat pengetahuan peserta sehingga materi dapat diberiken dengan maksimal.

\section{UCAPAN TERIMAKASIH}

Terimakasih diucapkan kepada Pimpinan Fakultas IImu Kesehatan Universitas Muhammadiyah Malang yang telah mendanai Block Grant ini dengan dana Block Grant PPM tahun anggaran $2019 / 2020$

\section{DAFTAR RUJUKAN}

Adnyana, I. G. L. A., \& Purnami, N. M. (2016). PENGARUH PENDIDIKAN KEWIRAUSAHAAN, SELF EFFICACY DAN LOCUS OF CONTROL PADA NIAT BERWIRAUSAHA. E-Jurnal Manajemen Unud, 5(2), 1160-1188.

Anggraeni, P., \& Akbar, A. (2018). Kesesuaian Rencana Pelaksanaan Pembelajaran Dan Proses Pembelajaran. JURNAL PESONA DASAR, 6(2), 55-65.

Dentchev, N., Baumgartner, R., Dieleman, H., Jóhannsdóttir, L., Jonker, J., Nyberg, T., Rauter, R., Rosano, M., Snihur, Y., Tang, X., \& van Hoof, B. (2016). Embracing the variety of sustainable business models: social entrepreneurship, corporate intrapreneurship, creativity, innovation, and other approaches to sustainability challenges. Journal of Cleaner Production, 113, 1-4. https://doi.org/10.1016/j.jclepro.2015.1 0.130

Dewi, R. R., \& Hadi, S. (2019). Transformasi Model Pembelajaran Mata Kuliah Kewirausahaan Dengan Brainstorming Dan Pengalaman Belajar Langsung Bagi Mahasiswa. Research Fair Unisri, 3(1), 476-487.

Huda, S., \& Kusumawati, D. (2019). Muhammadiyah Sebagai Gerakan Pendidikan. Tarlim : Jurnal Pendidikan Agama Islam, 2(2), 163. https://doi.org/10.32528/tarlim.v2i2.260 7

Jaharuddin, J., Purnawan, I., Mujiastuti, R., Muthmainnah, R. N., \& Prasetyawati, M. (2019). Strategi Melahirkan Mahasiswa Pengusaha Pemula (Studi Kasus Mahasiswa Universitas
Muhammadiyah Jakarta). Jurnal Kewirausahaan Dan Bisnis, 24(13), 25. https://doi.org/10.20961/jkb.v24i13.293 10

Martín-Rojas, R., Garrido-Moreno, A., \& GarcíaMorales, V. J. (2020). Fostering Corporate Entrepreneurship with the use of social media tools. Journal of Business Research, 112(June), 396412.

https://doi.org/10.1016/j.jbusres.2019.1 1.072

Rusydi, S. R. (2016). Peran Muhammadiyah (Konsep Pendidikan, Usaha-Usaha di Bidang Pendidikan dan Tokoh). Jurnal Tarbawi, 1(2), 139-148. https://doi.org/10.1017/CBO97811074 15324.004

Santy, N., Rahmawati, T., \& Hamzah, A. (2017). Pengaruh Efikasi Diri, Norma Subjektif, Sikap Berperilaku Dan Pendidikan Kewirausahaan Terhadap Intensi Berwirausaha. Jurnal Inspirasi Bisnis Dan Manajemen, 1(1), 63. https://doi.org/10.33603/jibm.v1i1.481

Suddaby, R., Viale, T., \& Gendron, Y. (2016). Reflexivity: The role of embedded social position and entrepreneurial social skill in processes of field level change. Research in Organizational Behavior, 36, 225-245. https://doi.org/10.1016/j.riob.2016.02.0 01

Türko, E. S. (2016). Business plan vs business model canvas in entrepreneurship trainings: A comparison of students' perceptions. Asian Social Science, 12(10), $55-62$. https://doi.org/10.5539/ass.v12n10p55 